RU Система терминообозначений восточных заимствований в современном русском языке

\begin{abstract}
Мухина Н. Н.
Аннотация. Цель исследования - определить место восточных заимствований в системе терминообозначений иноязычной лексики современного русского языка. В статье описаны видовые разновидности восточной лексики в русском языке. Предложена типология иноязычных слов, в основе которой лежит характер функционального предназначения слова. Определено родовое терминологическое словосочетание для обозначения слов, заимствованных из восточных языков. Научная новизна заключается в разработке шкалы градации регионально закрепленных иноязычий и определении в ней статуса восточных лексем. В результате доказано, что восточные заимствования входят в эквивалентную ассимилированную лексику и в лексику безэквивалентного характера, демонстрируя на шкале регионально закрепленных иноязычий четвертую степень градации в порядке ослабления дифференцирующего признака.
\end{abstract}

\title{
EN Typological Classification of Eastern Borrowings in the Modern Russian Language
}

\author{
Mukhina N. N.
}

\begin{abstract}
The paper proposes a typological classification of eastern borrowings in the modern Russian language. The article describes types of eastern vocabulary, proposes a functional typology of foreign vocabulary and identifies the most appropriate generic term for eastern borrowings. Scientific originality of the study lies in the fact that the author tries to systematize the borrowed vocabulary and to reveal the status of "eastern" words. As a result, it is proved that eastern borrowings include assimilated equivalent words and non-equivalent words. According to the degree of a differential seme manifestation, they can be classified as orientalisms.
\end{abstract}

\section{Введение}

Заимствования из восточных языков представляют одну из наиболее значимых страниц в развитии словарного состава русского языка. Очевидно, что в ближайшее время этот процесс будет только усиливаться. В связи с интенсификацией процесса заимствования на современном этапе, безусловно, наблюдается и усложнение терминологической системы, обслуживающей иноязычную лексику. Актуальность исследования обусловлена стремлением привести в систему терминологический ряд, номинирующий заимствованные слова, и уточнить в ней статус восточных заимствований.

В работе были поставлены следующие задачи:

1. Определить наиболее предпочтительное родовое наименование для слов, заимствованных из восточных языков.

2. Описать видовые разновидности лексики ориентального происхождения.

3. Определить статус восточных заимствований в системе терминообозначений иноязычной лексики.

В процессе исследования были использованы следующие методы: описательный, включающий в том числе приемы классификации и типологизации эмпирического материала, и сравнительно-сопоставительный.

Теоретической базой послужили работы по изучению процессов заимствования и неологизации, протекающих в современном русском языке (Е. В. Сенько [18], 2007; Е. В. Маринова, 2008 [13]), а также работы, посвященные изучению заимствованных из восточных языков слов (Аль Шаммари Маджида Джамиль Ашур, 2015 [1]; Г. Х. Гилазетдинова, 2011 [7]). 
Практическая значимость обусловлена возможностью применения полученных результатов в университетских курсах, посвященных лексикологии и современному состоянию восточно-русских языковых контактов.

Непрерывное обогащение русского языка иноязычными элементами, их разная адаптация, увеличение этимологического, тематического, функционального разнообразия инолексем приводит к сложности, многоуровневости пласта иноязычных слов в русском языке.

Отсутствие единой типологии указанных лексических единиц ведет к терминологическому разнобою в системе специальных наименований.

Можно, например, отметить отсутствие единого взгляда на определение наиболее частотных терминов «заимствование» и «иностранное слово».

Так, в «Лингвистическом энциклопедическом словаре» подчеркивается следующее: «...заимствования приспосабливаются к системе заимствующего языка и зачастую настолько им усваиваются, что иноязычное происхождение таких слов не ощущается носителями этого языка и обнаруживается лишь с помощью этимологического анализа» [12, с. 158].

Согласно мнению Л. П. Крысина, «в понятие “иностранное слово” входит и указание на источник заимствования - западноевропейский или восточный язык» [10, с. 143].

Еще один широко распространенный термин - «иноязычное слово», под которым понимают и полностью освоенные иностранные слова, и неисконные лексические единицы с явно выраженными признаками иноязычного происхождения; в последнем значении рассматриваемый термин иногда приравнивается к специальному обозначению «иностранное слово», названному выше [13, с. 19]. Термин «заимствование» также понимается неоднозначно: в предметном и процессуальном значении.

\section{Родовой термин для слов, заимствованных из восточных языков}

В число видовых разновидностей иноязычных слов входят и специальные наименования слов, заимствованных русским языком из восточных языков. Понятие «восточные языки», в свою очередь, включает в себя целый ряд видовых наименований, обозначающих несколько разносистемных языков: тюркские, еврейский, монгольские, индийские, иранские, а также арабский, китайский, корейский, японский.

Для обозначения заимствований из восточных языков в русской лексической системе языка используются термины «ориентализм», «восточные заимствования», «восточная лексика», «восточные слова».

Термин «ориентализм» - один из частотных в современном научном обиходе. В классическом понимании указанное терминологическое обозначение проецировалось на исламский мир, в том числе Ближний Восток, территорию Турции и государств Средней Азии; в последнее время объем данного понятия расширился, в результате чего термин «ориентализм» связан и с изучением народов Дальнего Востока, Юго-Восточной и Южной Азии [8].

В толковых словарях термин «ориентализм» определяется следующим образом:

Толковый словарь русского языка (под ред. Д. Н. Ушакова. М., 1940): ориентализм - изучение Востока, увлечение Востоком, его культурой; восточный, ориентальный оттенок в чем-либо [20];

Толковый словарь иноязычных слов Л. П. Крысина (М., 2005): ориенталистика - восточная филология, наука о культуре, языках и литературе народов Востока, востоковедение [11].

Дальнейшее расширение значения термина «ориентализм» приводит к его новому пониманию как особого мировоззрения, определенного образа мышления. Именно этот аспект лексического значения термина подчеркивал Э. Саид, популяризировавший термин и утверждавший, что «понятие Восток (Ориент) было преднамеренно придумано в Европе, которой был нужен некий инаковый чужой» [15, с. 102].

Таким образом, ориентализм - понятие не только географическое, но и культурное и политическое.

Термин «ориентализм» широко используется и в работах лингвистического характера. Расширение сферы употребления термина естественно: оно обосновано тем, что язык есть воплощение культуры и духовной жизни народа. Так, А. И. Бушеева пишет: «Под ориентализмами мы понимаем неоднородные лексемы, принадлежащие разным языкам, заимствованные преимущественно из алтайской группы тюркских, а также иранских и арабо-семитских языков» [5, с. 3].

Как уже указывалось, наряду с рассматриваемым термином употребляются следующие терминологические словосочетания: восточная лексика, восточные слова, восточные заимствования. Их принято считать синонимичными данному специальному обозначению, однако в последнем из названных словосочетаний можно усмотреть оттенок значения, подчеркивающий, что данные лексические единицы заимствованы другим языком из лексики восточных языков.

Среди специальных наименований слов, заимствуемых русским языком из восточных языков, наиболее правомерным, на наш взгляд, представляется употребление терминологического словосочетания «восточные заимствования». Выбор данного термина можно объяснить следующим образом: синонимическое обозначение «ориентализм» неудобно в связи с его полисемичностью, хотя и в разных терминологических системах; термин «восточная лексика» исключает из своей семантической структуры сему «перемещение из одного языка в другой», акцентируя сему «локализованность», в связи с этим указанный термин требует определенной синтагматики для уточнения своего содержания; термины «евразизмы», «азиатизмы», как и термин «ориентализмы», полисемичны, акцентируют локальную маркировку слова-понятия; специальное наименование «восточные 
заимствования» подчеркивает, что данные лексические единицы заимствованы другим языком из лексики восточных языков, данная модель регулярна, ср.: английские заимствования, французские заимствования и т.п.

\section{Типовые разновидности лексики ориентального происхождения}

Термины «ориентализм», «восточные слова», «восточные заимствования», «восточная лексика» в определенной степени коррелируют с терминами «экзотизм», «этнографизм», «регионализм», «локализм»; данное утверждение основывается на общем для всех названных терминов функциональном аспекте их рассмотрения. Однако их функционально-территориальная маркированность неидентична:

- этнографизмы - слова, которые не имеют соответствующего понятия в сопоставляемом языке, так как отсутствует сам обозначаемый предмет и обозначающие, таким образом, собственно реалии, в силу чего этнографизмы номинируют отдельные лексико-тематические группы экзотической лексики: бинди (цветная точка, которую индианки рисуют в центре лба), джонка (традиционное китайское и японское парусное судно для плавания по рекам и вблизи морского побережья) и т.п.;

- регионализмы - лексемы, распространенные в определенном регионе; в составе региональной лексики могут быть и слова литературного языка, и диалектные формы, и жаргонизмы, и топонимы; таким образом, региональная лексика имеет определенную структуру [4, с. 31];

регионализмы «локально закреплены в словарях литературного языка в отличие от диалектизмов, которые имеют общую помету “обл.”; от диалектизмов регионализмы отличаются и отсутствием социальной закрепленности» [16, с. 144]: курень на Дону и Кубани: ‘изба, дом’;

- локализм во многих случаях определяется как диалектизм (синоним «провинциализм»), то есть как местное слово, однако под указанным термином понимаются национальные особенности русского языка, обусловленные его функционированием за пределами России, в результате русский язык с чертами интерференции оказывается локализованным; возникают его белорусский, эстонский и т.п. ареалы. Ф. П. Филин подчеркивал: «К диалектным локализмам прибавляются локализмы инонациональные» [19, с. 142]; Л. Г. Самотик, исследуя подобные слова, называет их нациолектизмами: «Нациолектизмы - слова в русской речи нерусских с устойчивыми явлениями интерференции; внелитературная лексика, передающая маркированную речь нерусских»; в частности, узбек может назвать словом арык любую канаву, белорус устойчиво произносит (р) на месте (p'): (зоркъ) - зорька и т.п. [17, с. 180].

Аналогичную точку зрения высказывает и И. У. Асфандияров. По его мнению, региональную лексику составляют слова, используемые русским языком в пределах какого-либо конкретного региона, например Средней Азии и Казахстана: бахши 'народный певеи', патыр 'праздничная лепешка' и др.; что касается локализмов, то они представлены словами, принадлежащими только одному из национальных языков народов Средней Азии и Казахстана: кыштак 'деревня', ширдак 'молоко' (из киргизского языка); гельнедже 'невеста', вахарман ‘дыня’, кетени ‘название национального платья’ (из туркменского); анзур 'лук’ (из таджикского) [2, с. 26-33].

Таким образом, можно установить определенную градацию пространственного характера в семантике рассмотренных видовых терминов, именующих безэквивалентные слова: экзотизм - этнографизм - регионализм - локализм.

В современной лингвистике значительной регулярностью обладает и термин «реалия», распространение которого обусловлено практикой переводоведения.

Под этим термином понимается «предмет, понятие, явление, характерное для истории, быта, культуры, уклада определенного народа. Реалия - также слово, обозначающее такой предмет, явление, понятие...» [14].

Этим термином также обозначают слова, транслирующие явления, которых нет в практическом опыте людей, говорящих на другом языке [3, с. 95].

С. Влахов, С. Флорин в своих трудах отмечали, что «безэквивалентная лексика не имеет переводческих эквивалентов в языке перевода; реалии - это часть безэквивалентной лексики, носители национального или исторического колорита...» [6, с. 47].

В свою очередь, В. П. Конецкая делит реалии на: универсалии - эквивалентная лексика, квазиреалии фоновая лексика, собственно реалии - безэквивалентная лексика [9].

Таким образом, термин «реалия» вписывается в ряд «безэквивалентная лексика», «экзотизм», а также «национально-окрашенная лексика», «лакуна», «культурно-коннотативные слова» и др., а по мнению С. Влахова, С. Флорина, соотносится с термином «этнографизм».

Восточная лексика - понятие неоднородное по своему объему и, соответственно, содержанию, что обусловлено базовым для него термином «восточные языки». Следствие этого - выделение нескольких референтов в семантической структуре рассматриваемого понятия:

- тюркизмы, заимствования из различных тюркских языков;

- арабизмы, проникшие в русскую языковую систему из арабского языка;

- японизмы - заимствования из японского языка;

- китаизмы - заимствования из китайского языка;

- гебраизмы - слова и выражения, пришедшие в русский язык из еврейского языка (иврит); и т.п.

Следует отметить еще один термин, коррелирующий с термином «восточное заимствование», это термин «ксенизм». Последний есть иноязычное слово, отражающее быт страны-источника; ксенизмы выделяются из европеизмов, которые противопоставляются азиатизмам, включающим в себя экзотизмы. 
Таким образом, в современной лексикологии можно встретить следующие терминологические обозначения восточных заимствований: экзотизмы, этнографизмы, регионализмы, локализмы, ксенизмы, реалии, тюркизмы, арабизмы, гебраизмы, иранизмы, японизмы, китаизмы, монголизмы, кореизмы, индоизмы.

\section{Шкала градации регионально закрепленных иноязычий}

Обзор терминологического корпуса, обслуживающего иноязычную лексику, показывает, что фонд данных специальных наименований неоднозначен и несистемен. Данное обстоятельство объясняется отсутствием единой стратификации иноязычной лексики. Наиболее противоречивым предстает фонд неосвоенной иноязычной лексики, в частности безэквивалентной, что обнаруживается как в толковании отдельных терминов, так и в их соотношении друг с другом. Возможно, что подобного рода трудности обусловлены разноаспектностью процесса заимствования на современном этапе русского языкового развития.

В настоящей работе предпринимается попытка систематизировать указанный терминологический фонд следующим образом.

Доминантой является родовой термин «иноязычное слово» (= иноязычная лексика, слова иноязычного происхождения, лексика иноязычного происхождения); не включен в вышеприведенный терминоряд термин «иностранные слова», так как необходимая прозрачность внутренней формы отсутствует, а регулярность его употребления объясняется данью традиции и лексикографической практикой [13, с. 22].

Вслед за Е. В. Мариновой в качестве основных видовых разновидностей указанных понятий следует считать эквивалентную и безэквивалентную лексику.

Эквивалентная лексика представлена оппозицией «ассимилированные иноязычные слова» - «неассимилированные иноязычные слова», включающей во второй своей части частную оппозицию «вкрапления варваризмы», в первой - европеизмы (сфера употребления) и ориентализмы (универсалии).

Безэквивалентная лексика включает целый ряд видовых разновидностей иноязычных слов, которые, на наш взгляд, противопоставляются по признаку «локализация денотата/референта»: экзотизмы, этнографизмы, регионализмы, локализмы, ксенизмы, реалии, ориентализмы, тюркизмы, арабизмы, гебраизмы, иранизмы, японизмы, китаизмы, монголизмы, кореизмы, индоизмы и т.п. В связи со сказанным предполагается градация регионально закрепленной иноязычной лексики в порядке ослабления их дифференцирующей семы:

экзотизмы (= ксенизмы, реалии) - наименования реалий, характерных жизненному укладу другой страны: муфтий ‘высшее духовное лицо у мусульман';

этнографизмы (= собственно реалии) - часть экзотизмов, обозначающих собственно реалии: бинди 'цветная точка, которую индианки рисуют в центре лба, так называемый «третий глаз» ';

локализмы - слова в русской речи нерусских с устойчивыми явлениями интерференции: арык 'гидротехническое сооружение в виде оросительного канала';

восточные заимствования (= евразизмы, азиатизмы) - заимствования из восточных языков, восточная лексика, ориентализмы - собственно реалии, квазиреалии, включающие тюркизмы, арабизмы, японизмы, китаизмы и т.п.: суши ‘блюдо в традиционной японской кухне’;

регионализмы - слова, распространенные в том или ином регионе, чаще - в бывших советских республиках: амбал 'князь остяков (хантов) и татар, обитавших в XVI-XVII веках в бассейне реки Сылва'.

\section{Заключение}

Несмотря на то, что проблеме заимствования посвящено множество исследований, в языкознании остается много вопросов, одним из которых является смешение терминов. Заимствование лексики восточного происхождения, активизировавшееся на настоящем этапе, требует определенного упорядочения терминологического аппарата. Проведенное исследование позволяет сделать следующие выводы.

1. Среди специальных наименований слов, заимствуемых русским языком из восточных языков, наиболее правомерным, на наш взгляд, представляется употребление терминологического словосочетания «восточные заимствования».

2. Восточные заимствования в современной лексикологии представлены следующими видовыми разновидностями: экзотизмы, этнографизмы, регионализмы, локализмы, ксенизмы, реалии, тюркизмы, арабизмы, гебраизмы, иранизмы, японизмы, китаизмы, монголизмы, кореизмы, индоизмы.

3. Статус восточных заимствований имеет двоякий характер: они входят в эквивалентную ассимилированную лексику и в лексику безэквивалентного характера, демонстрируя на шкале градации регионально закрепленных иноязычий четвертую степень в порядке ослабления дифференцирующего признака.

В связи с тем, что изучение новых лексических единиц играет большую роль в современном языкознании как в социально-историческом, так и лингвистическом отношении, а также учитывая тот факт, что словарный состав имеет тенденцию к расширению за счет актуализации различными способами слов, заимствованных ранее, перспективы дальнейшего исследования представляются в изучении еще только формирующегося терминологического аппарата актуализированных заимствований. 


\section{Источники | References}

1. Аль Шаммари Маджида Джамиль Ашур. Актуальные арабизмы религиозного содержания (на материале современных словарей иностранных слов) // Известия Южного федерального университета. Филологические науки. 2015. № 5. С. 102-107.

2. Асфандияров И. У. Восточная лексика в русском языке. Ташкент: Фан, 1991. 121 с.

3. Бархударов Л. С. Язык и перевод: вопросы общей и частной проблемы перевода. М.: Междунар. отношения, 1975. 240 с.

4. Бородина М. А. Диалекты или региональные языки? (К проблеме языковой ситуации в современной Франции) // Вопросы языкознания. 1982. № 5. С. 29-38.

5. Бушеева А. И. Ориентализмы в системно-функциональном аспекте: дисс. ... к. филол. н. Чебоксары, 2009. 202 с.

6. Влахов С., Флорин С. Непереводимое в переводе: учебное пособие. М.: Международные отношения, 1980. 342 с.

7. Гилазетдинова Г. Х. Восточные заимствования в языке Московской Руси: дисс. ... д. филол. н. Казань, 2011. 456 с.

8. Жусипбек Г. Ориентализм стереотипы, факты, попытка анализа [Электронный ресурc]. URL: https://www.proza. ru/2012/06/19/1958 (дата обращения: 05.06.2021).

9. Конецкая В. П. Лексико-семантическая характеристика языковых реалий // Великобритания: лингвострановедческий словарь. М.: Рус. яз., 1980. С. 463-466.

10. Крысин Л. П. Иноязычное слово в контексте современной общественной жизни // Русский язык конца XX столетия (1985-1995) / под ред. Е. А. Земской. М.: Языки русской культуры, 2000. С. 142-161.

11. Крысин Л. П. Толковый словарь иноязычных слов. М.: Эксмо, 2005. 939 с.

12. Лингвистический энциклопедический словарь / гл. ред. В. Н. Ярцева. М.: Сов. энциклопедия, 1990. 685 с.

13. Маринова Е. В. Иноязычные слова в русской речи конца XX - XXI в.: проблемы освоения и функционирования. М.: ЭЛПИС, 2008. 495 с.

14. Реалия [Электронный ресурс]. URL: http://feb-web.ru/feb/kle/kle-abc/ke6/ke6-2272.htm (дата обращения: 05.06.2021).

15. Саид Э. Ориентализм: западные концепции Востока. СПб.: Русский мир, 2006. 637 с.

16. Самотик Л. Г. Географическое варьирование лексики литературного языка. Статья 1. Регионализмы // Русский язык в географической проекции: межвуз. сб. научн. трудов. Красноярск: Изд-во РИО КГПУ, 2000. С. 143-151.

17. Самотик Л. Г. Лексика современного русского языка: учеб. пособие. Красноярск: Изд-во КГПУ им. В. П. Астафьева, 2011. 496 с.

18. Сенько Е. В. Неологизация в современном русском языке: межуровневый аспект. СПб.: Наука, 2007. 354 с.

19. Филин Ф. П. Истоки и судьбы русского литературного языка / АН СССР, Институт русского языка. М.: Наука, 1981. $328 \mathrm{c}$.

20. https://dic.academic.ru/dic.nsf/ushakov/904854 (дата обращения: 05.06.2021).

\section{Информация об авторах | Author information}

RU Мухина Наталья Николаевна ${ }^{1}$, к. филол. н.

${ }^{1}$ Северо-Осетинский государственный университет имени К. Л. Хетагурова, г. Владикавказ

EN Mukhina Natalya Nikolaevna ${ }^{1}, \mathrm{PhD}$

${ }^{1}$ North Ossetian State University after Kosta Levanovich Khetagurov, Vladikavkaz

${ }^{1}$ nest.nataly@mail.ru

\section{Информация о статье | About this article}

Дата поступления рукописи (received): 11.05.2021; опубликовано (published): 30.06.2021.

Ключевые слова (keywords): безэквивалентная лексика; варваризм; ориентализм; экзотизм; этнографизм; non-equivalent vocabulary; barbarism; orientalism; exotism; ethnographism. 